\title{
Supporting information: Zebrafish Oatp1d1 acts as cellular efflux transporter of the anionic herbicide bromoxynil
}

Katharina Halbach ${ }^{1}$, Silke Aulhorn ${ }^{2}$, Oliver Jens Lechtenfeld ${ }^{1}$, Marion Lecluse ${ }^{1}$, Sophia Leippe ${ }^{1}$, Thorsten Reemtsma ${ }^{1,3}$, Bettina Seiwert ${ }^{1}$, Stephan Wagner ${ }^{1}$, Jörg König ${ }^{4}$, Till Luckenbach ${ }^{2 *}$

${ }^{1}$ Department of Analytical Chemistry, Helmholtz Centre for Environmental Research - UFZ, D -

04317 Leipzig, Germany

${ }^{2}$ Department of Bioanalytical Ecotoxicology, Helmholtz Centre for Environmental Research - UFZ, D

- 04317 Leipzig, Germany

${ }^{3}$ Institute of Analytical Chemistry, University of Leipzig, D - 04317 Leipzig, Germany

${ }^{4}$ Institute of Experimental and Clinical Pharmacology and Toxicology, Friedrich-Alexander

Universität Erlangen-Nürnberg, D - 91054 Erlangen, Germany

*Corresponding author: Till Luckenbach; till.luckenbach@ufz.de

\section{Table of contents:}

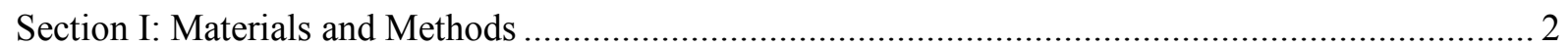

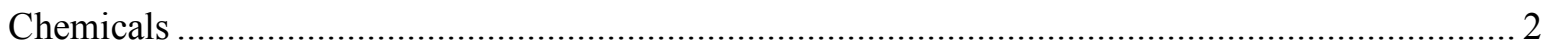

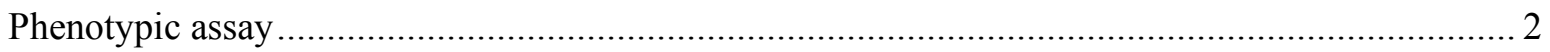

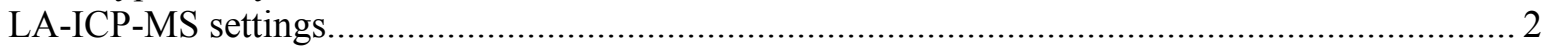

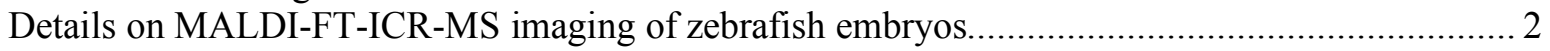

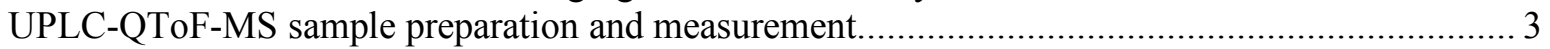

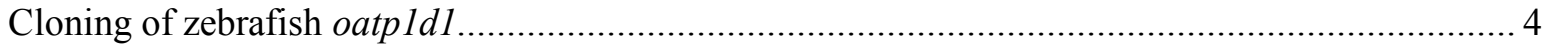

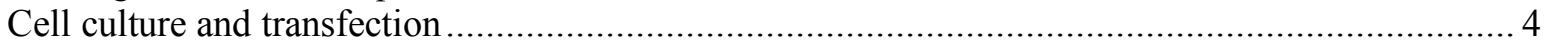

Section II: Dose-response curves for bromosulfophthalein and bromoxynil ................................... 5

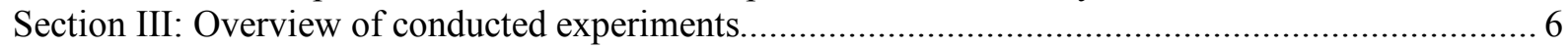

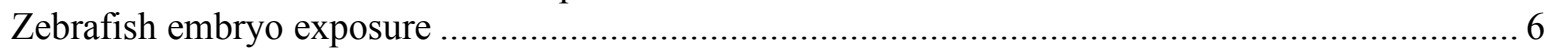

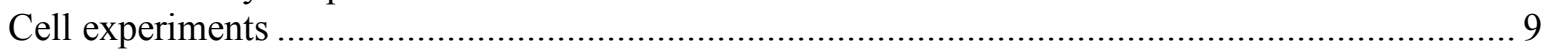

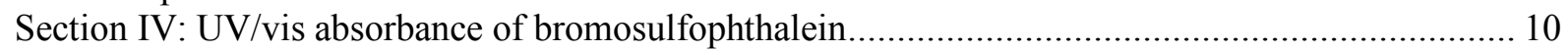

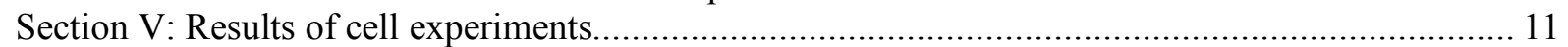

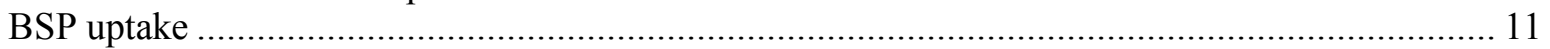

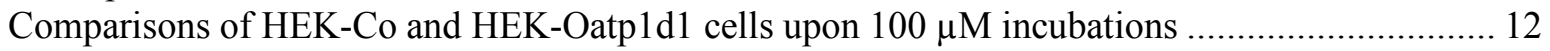

BSP effects on uptake of bromoxynil, diclofenac and carbamazepine (100 $\mu \mathrm{M}$ incubations) ......... 13

CsA effects on uptake of BSP, bromoxynil, diclofenac, and carbamazepine ............................... 15

Cellular accumulation bromoxynil and diclofenac upon mixed incubations................................. 16

Section VI: Results of zebrafish embryo exposure experiments .................................................... 17

Phenotype effects of the test compounds in zebrafish embryos.................................................. 17

Internal concentrations upon mixed exposure to bromoxynil and diclofenac .............................. 21

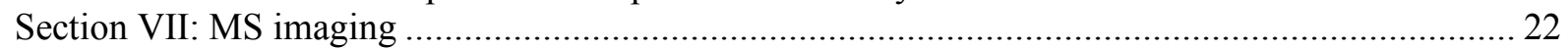

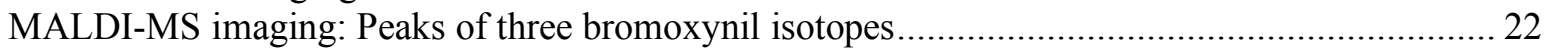

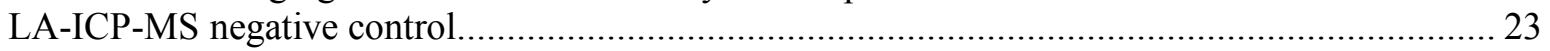

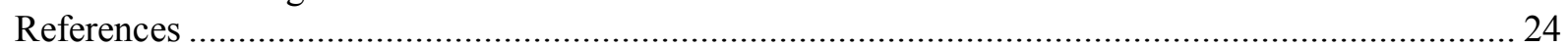




\section{Section I: Materials and Methods}

\section{Chemicals}

For experiments with cells and zebrafish embryos, the following chemicals were used for the exposure and incubation experiments: bromoxynil (CAS 1689-84-5, Seelze, Sigma-Aldrich), bromosulfophthalein (BSP, CAS 71-67-0, Cayman chemical), $\left[{ }^{3} \mathrm{H}\right]$-BSP (Hartmann Analytic, Braunschweig, Germany), carbamazepine (CAS 298-46-4, ICN Biomedicals), cyclosporin A (CsA, CAS 59865-13-3, LC Laboratories), diclofenac sodium salt (CAS 15307-79-6, Sigma-Aldrich). Chemicals were directly dissolved in ISO-water ${ }^{1}$ for the exposure experiments with zebrafish embryos. For uptake quantification with ultraperformance liquid chromatography quadrupole-time-of-flight MS (UPLC-QToF-MS; with cells and with zebrafish embryos) and MS-imaging measurements (with zebrafish embryos), the following chemicals were used: bromoxynil-d2 (CAS 1219798-95-4, NEOCHEMA), diclofenac-d4 (CAS 153466-65-0, HPC standards), carbamazepine-d10 (CAS 13218378-9, Sigma-Aldrich), 9-aminoacridine (9-AA, CAS 90-45-9, Sigma-Aldrich), Neg-50 Frozen Section Medium (Thermo Scientific).

\section{Phenotypic assay}

For the assessment of phenotypic effects, we distinguished between three effect categories: lethal, sublethal and teratogenic effects. Lethal effects are indicated by the endpoints coagulation (k), no formations of somites (nosf), no detachment of tail (nodt) and/or no heartbeat (nohb). If at least one of the four effects is observed, the embryo is classified as dead. Teratogenic effects are indicated by developmental retardation (ret) and by malformations of the embryonic body, such as scoliosis (sco). All other observed abnormalities, like no blood circulation (nobc), decreased heart frequency (hf), no pigmentation (nopig) or pericard edema (EdP) are endpoints of sublethal effects. Furthermore, hatching of the embryos was registered.

\section{LA-ICP-MS settings}

The following ICP-MS settings were used: $1000 \mathrm{~W}$ radiofrequency power, $12 \mathrm{~L} / \mathrm{min}$ plasma gas (argon), $2.3 \mathrm{~L} / \mathrm{min}$ auxiliary gas (argon), $1 \mathrm{~s}$ integration time with a base interval of $100 \mathrm{~ms}$. The following laser parameters were applied: $50 \mu \mathrm{M}$ spot size, $100 \mathrm{~Hz}$ laser frequency, $50 \mu \mathrm{m} / \mathrm{s}$ scan speed, $1.65 \mathrm{~J} / \mathrm{cm}^{2}$ fluence. ${ }^{13} \mathrm{C},{ }^{12} \mathrm{C},{ }^{79} \mathrm{Br}$, and ${ }^{81} \mathrm{Br}$ were measured. Results for ${ }^{13} \mathrm{C}$ and ${ }^{79} \mathrm{Br}$ are reported.

\section{Details on MALDI-FT-ICR-MS imaging of zebrafish embryos}

For MALDI-FT-ICR-MS imaging, upon exposure to test compounds the embryos were carefully placed in NEG-50 Frozen Section Medium (Thermo Scientific) with a plastic pipette taking care to completely cover the embryos with the medium, excess water was removed, and the embryos were then transferred 
to a cryomold containing NEG-50 medium. The cryomolds with the embryos were immediately placed on dry ice and frozen, wrapped in aluminum foil, and stored until sectioning at $-80{ }^{\circ} \mathrm{C}$. $24 \mathrm{~h}$ prior to sectioning, the cryomolds were placed in a microtome (Cryo-Star HM 560, Microm International, Walldorf, Germany) at $-17^{\circ} \mathrm{C} .12 \mu \mathrm{M}$ sections were cut and transferred to an ITO-coated glass slide (Bruker, Bremen, Germany) and thaw-mounted. Glass slides were dried and stored for a maximum of 5 days in a desiccator at 200-300 mbar. Prior to analysis, marks were drawn onto the glass slides with a white pen, and the slides were weighed and scanned (OpticLab H580, Plustek, Ahrensfelde, Germany). The organic matrix molecule 9-AA was applied with a sublimation device. ${ }^{2}$ A sand bath to heat the sublimation device was heated for $1 \mathrm{~h}$ at $150{ }^{\circ} \mathrm{C}$, and then $300 \mathrm{mg}$ of 9-AA were filled into the sublimation device, ${ }^{2}$ and the slide was mounted with a double-sided adhesive tape. Ice was filled into the top chamber. Vacuum (2-5 mbar) was applied, and the sublimation was stopped after $30 \mathrm{~min}$. The deposited amount of 9-AA was 91 and $117 \mu \mathrm{g} / \mathrm{cm}^{2}$ 9-AA on the two measured slides, respectively.

MALDI-MS imaging measurements were carried out with a MALDI ion source $(1 \mathrm{kHz}$ Laser of $335 \mathrm{~nm}$, Smartbeam II, Bruker Daltonics, Bremen, Germany) coupled to an FT-ICR-MS (solarix XR 12T, Bruker Daltonics, Bremen, Germany). Parameter setting and measurement were conducted with ftms Control Software (Version 2.10, Bruker Daltonics, Bremen, Germany) and teaching of the position with Flex Imaging Software (Version 4.1, Bruker Daltonics, Bremen, Germany). Bromoxynil was measured in negative mode with $15 \%$ laser power, 500 shots, $1000 \mathrm{~Hz}$, minimum laser focus, $25 \mu \mathrm{M}$ raster width, and applied isolation windows $(\mathrm{m} / \mathrm{z} 283 \pm 20,308 \pm 30,335 \pm 20,365 \pm 36,392 \pm 13,414 \pm 26,436 \pm$ $14,458 \pm 26,484 \pm 22,505 \pm 16,540 \pm 50,592 \pm 50,618 \pm 2$ ). The isolation windows were chosen in order to detect bromoxynil and previously reported ${ }^{3}$ transformation products. Bromoxynil was detected as $[\mathrm{M}-\mathrm{H}]^{-}(275.84671 \mathrm{~m} / \mathrm{z} \pm 0.19313 \mathrm{mDa})$. Bromoxynil was confirmed by the detection of the three most abundant isotope peaks $(273.84877 \mathrm{~m} / \mathrm{z} \pm 0.30818 \mathrm{mDa}, 275.84671 \mathrm{~m} / \mathrm{z} \pm 0.19313 \mathrm{mDa}, 277.8447$ $\mathrm{m} / \mathrm{z} \pm 0.27828 \mathrm{mDa}$, Figure S10).

\section{UPLC-QToF-MS sample preparation and measurement}

Embryos were extracted with $500 \mu \mathrm{L}$ methanol containing the deuterated internal standard. Extraction was performed by placing the samples in an ultrasonic bath at room temperature for $15 \mathrm{~min}$, followed by shaking for $15 \mathrm{~min}$, and centrifugation at $13 \mathrm{rpm}$ for $15 \mathrm{~min}$. The supernatant was diluted with ultrapure water to 50:50 ultrapure water/methanol (v/v). Samples were stored at $-20{ }^{\circ} \mathrm{C}$ until measurement.

Lysed cells were centrifuged (15 min at $13 \mathrm{rpm}$ ) and diluted with ultrapure water (with dissolved internal standards), yielding 50:50 (v/v) ultrapure water/methanol at the day of measurement.

Details of bromoxynil and carbamazepine measurements can be found in Halbach et al. ${ }^{3}$ Diclofenac was measured with the same method parameters as bromoxynil and detected in negative mode $(\mathrm{m} / \mathrm{z} 250.019$ at $10.60 \mathrm{~min}$, d4-diclofenac $\mathrm{m} / \mathrm{z} 254.045$ at $10.58 \mathrm{~min}$ ). 


\section{Cloning of zebrafish oatp $1 d 1$}

The oatpld 1 cDNA encoding zebrafish Oatp1d1 was cloned by a reverse transcriptase polymerase chain reaction-based approach using the primer oOatp1d1-5'for (5'-gga cac cat gag tac gga gaa-3') and oOatp1d1-RT.rev (5'-gcc tgc agg act tca gat gg-3') and zebrafish liver total RNA as a template. The amplified fragment was cloned into the cloning vector pCR2.1.TOPO (Thermo Fisher Scientific) and finally subcloned into the expression vector pcDNA3.1(+) (Thermo Fisher Scientific), resulting in the plasmid pOatp1d1.31. The sequence was verified and base pair exchanges (compared to the reference sequence NM_001348986.1 $1^{4}$ ) resulting in amino acid exchanges after translation were corrected by sitedirected mutagenesis. The final cDNA encodes for an Oatp1d1 protein 100\% identical to the protein encoded by the reference sequence.

\section{Cell culture and transfection}

Human embryonic kidney (HEK293) cells were cultured in minimal essential medium containing 10\% heat-inactivated fetal bovine serum, $100 \mathrm{U} / \mathrm{mL}$ penicillin, and $100 \mu \mathrm{g} / \mathrm{mL}$ streptomycin at $37^{\circ} \mathrm{C}$ and $5 \%$ $\mathrm{CO}_{2}$. The cells were routinely cultivated by trypsinisation. HEK293 cells were transfected with the plasmid pOatp1d1.31 using Effectene transfection reagent (Qiagen $\mathrm{GmbH}$ ). After geneticin (G418, $800 \mu \mathrm{g} / \mathrm{mL}$ ) selection, single colonies were characterized for oatpldl (slcoldl) expression by real-time quantitative PCR. The clone (HEK-drOatp1d1) with the highest oatpld1 expression (related to the expression of the housekeeping gene $\beta$-actin) was selected for further transport experiments. 


\section{Section II: Dose-response curves for bromosulfophthalein and bromoxynil}

a)

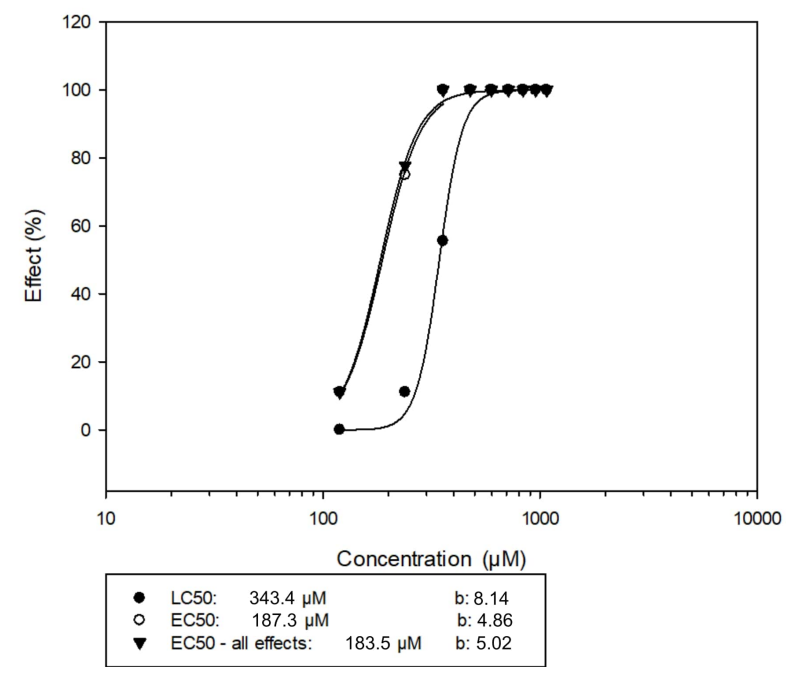

b)

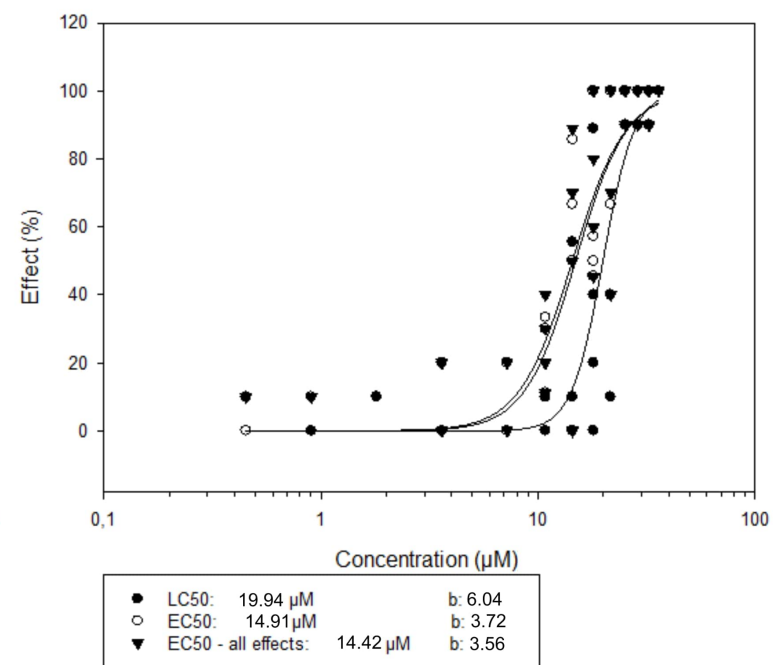

Figure S1. Effects of a) bromosulfophthalein and b) bromoxynil on zebrafish embryos in a $96 \mathrm{~h}$ toxicity test. Recorded were mortality and sublethal effects. $\mathrm{N}=9$ for each data point. The regression was modeled with the 4-parameter HILL equation: $\mathrm{f}=\mathrm{y} 0+(\mathrm{a}-\mathrm{y} 0) /\left(1+\left(\mathrm{EC} 50 / \mathrm{c}_{\mathrm{t}}\right)^{\mathrm{b}}\right) . \mathrm{y} 0$ : minimum, set to 0 ; a: maximum, set to 100; EC50: parameter value describing the compound concentration causing 50\% of the maximal effect; $b$ : HILL number; $c_{t}$ : concentration of compound t. EC: effect concentration; EC50 - all effects includes sublethal, lethal and teratogenic effects; LC: lethal concentration. 


\section{Section III: Overview of conducted experiments}

\section{Zebrafish embryo exposure}

Table S1. Overview of exposure experiments with the nominal concentrations of the test compounds and with the numbers of replicates in the different exposures. Each experiment was set up in two independent experiments with embryos from different egg batches (exposures A and B). Experiments were performed with the eggs of three egg batches. Egg batch 1: start of exposure with embryos at $1 \pm 1$ hpf, duration: $96 \mathrm{~h}$; egg batch 2: start of exposure with embryos at $1 \pm 1 \mathrm{hpf}$ and $72 \pm 1 \mathrm{hpf}$, duration: $24 \mathrm{~h}$; egg batch 3 : start of exposure with embryos at $1 \pm 1 \mathrm{hpf}$, duration: $96 \mathrm{~h}$ and embryos at $1 \pm 1 \mathrm{hpf}$ and $72 \pm 1 \mathrm{hpf}$, duration: $24 \mathrm{~h}$. For measured concentrations of test compounds in the exposure solutions, refer to Table S2.

\begin{tabular}{|c|c|c|c|c|c|c|c|}
\hline \multirow[t]{5}{*}{ Substance } & \multirow{5}{*}{$\begin{array}{l}\text { Diclofenac } \\
(\mu \mathrm{M})\end{array}$} & \multirow{5}{*}{$\begin{array}{l}\text { Bromoxynil } \\
(\mu \mathrm{M})\end{array}$} & \multirow{5}{*}{$\begin{array}{l}\text { Carbamazepine } \\
(\mu \mathrm{M})\end{array}$} & \multirow{5}{*}{$\begin{array}{l}\text { BSP } \\
(\mu \mathrm{M})\end{array}$} & \multicolumn{3}{|c|}{ Number of replicates with 3 embryos } \\
\hline & & & & & \multirow{4}{*}{$\begin{array}{l}\text { Experiment } 1 \\
96 \mathrm{~h} \text { exposure }\end{array}$} & \multirow{4}{*}{$\begin{array}{l}\text { Experiment } 2 \\
24 \mathrm{~h} \\
\text { exposures } \\
\text { (start } 1 \mathrm{hpf} \text { ) }\end{array}$} & \multirow{4}{*}{$\begin{array}{l}\text { Experiment } 3 \\
24 \mathrm{~h} \\
\text { exposures } \\
\text { (start } 72 \mathrm{hpf} \text { ) }\end{array}$} \\
\hline & & & & & & & \\
\hline & & & & & & & \\
\hline & & & & & & & \\
\hline Control & / & / & l & l & 5 & 4 & 4 \\
\hline BSP Control & / & / & / & 50 & 5 & 4 & 4 \\
\hline BSP Control & / & l & l & $100(\mathrm{EC} 5)$ & 7 & 4 & 4 \\
\hline Bromoxynil & / & $6.76(\mathrm{EC} 5)$ & l & l & 5 & 4 & 4 \\
\hline Bromoxynil & l & $6.76(\mathrm{EC} 5)$ & / & 50 & 5 & 4 & 4 \\
\hline Bromoxynil & / & $6.76(\mathrm{EC} 5)$ & / & 100 (EC5) & 5 & 4 & 4 \\
\hline Bromoxynil & / & $11.1(\mathrm{EC} 25)$ & l & l & 7 & 4 & 4 \\
\hline Bromoxynil & I & $11.1(\mathrm{EC} 25)$ & l & 50 & 7 & 4 & 4 \\
\hline Bromoxynil & l & $11.1(\mathrm{EC} 25)$ & I & 100 (EC5) & 7 & 4 & 4 \\
\hline Diclofenac & 4.63 (EC5) & l & l & l & 5 & 4 & 4 \\
\hline Diclofenac & 4.63 (EC5) & l & l & 50 & 5 & 4 & 4 \\
\hline Diclofenac & 4.63 (EC5) & l & l & 100 (EC5) & 5 & 4 & 4 \\
\hline Diclofenac & $5.24(\mathrm{EC} 25)$ & l & l & l & 7 & 4 & 4 \\
\hline Diclofenac & $5.24(\mathrm{EC} 25)$ & l & l & 50 & 7 & 4 & 4 \\
\hline Diclofenac & $5.24(\mathrm{EC} 25)$ & l & l & 100 (EC5) & 7 & 4 & 4 \\
\hline Diclofenac $^{\mathrm{a}}$ & 4.63 (EC5) & 6.76 (EC5) & & & & & \\
\hline Diclofenac $^{\mathrm{a}}$ & 4.63 (EC5) & $6.76(\mathrm{EC} 5)$ & & & & & \\
\hline
\end{tabular}




\begin{tabular}{|c|c|c|c|c|c|c|c|}
\hline \multirow[t]{5}{*}{ Substance } & \multirow[t]{4}{*}{ Diclofenac } & \multirow[t]{4}{*}{ Bromoxynil } & \multirow[t]{4}{*}{ Carbamazepine } & \multirow[t]{4}{*}{ BSP } & \multicolumn{3}{|c|}{ Number of replicates with 3 embryos } \\
\hline & & & & & Experiment 1 & Experiment 2 & Experiment 3 \\
\hline & & & & & $96 \mathrm{~h}$ exposure & $24 \mathrm{~h}$ & $24 \mathrm{~h}$ \\
\hline & & & & & & exposures & exposures \\
\hline & $(\mu \mathrm{M})$ & $(\mu \mathrm{M})$ & $(\mu \mathrm{M})$ & $(\mu \mathrm{M})$ & & (start $1 \mathrm{hpf}$ ) & (start $72 \mathrm{hpf}$ ) \\
\hline Carbamazepine & I & I & 231 (EC5) & I & 5 & 4 & 4 \\
\hline Carbamazepine & l & l & 231 (EC5) & 50 & 5 & 4 & 4 \\
\hline Carbamazepine & l & l & 231 (EC5) & 100 (EC5) & 5 & 4 & 4 \\
\hline Carbamazepine & I & l & $259(\mathrm{EC} 25)$ & l & 7 & 4 & 4 \\
\hline Carbamazepine & 1 & / & 259 (EC25) & 50 & 7 & 4 & 4 \\
\hline Carbamazepine & / & l & 259 (EC25) & 100 (EC5) & 7 & 4 & 4 \\
\hline
\end{tabular}

${ }^{\mathrm{a}}$ Only one independent experiment was conducted. 
Table S2. Measured concentrations in the exposure solutions

\begin{tabular}{llll}
\hline Substance & Experiment number & EC5 $(\mu \mathrm{M})$ & EC 25 $(\mu \mathrm{M})$ \\
\hline Bromoxynil & 1A & $9.63 \pm 2.26$ & $14.9 \pm 3.3$ \\
& 2A, 3A & $11.9 \pm 1.5$ & $21.3 \pm 2.9$ \\
& 1B, 2B, 3B & $10.6 \pm 2.4$ & $18.9 \pm 1.5$ \\
Diclofenac & 1A & & \\
& 2A, 3A & $2.67 \pm 0.43$ & $3.55 \pm 1.05$ \\
& 1B, 2B, 3B & $2.48 \pm 0.33$ & $3.07 \pm 0.49$ \\
Carbamazepine & 1A & & \\
& 2A, 3A & $217 \pm 14$ & $244 \pm 13$ \\
& 1B, 2B, 3B & $213 \pm 17$ & $214 \pm 20$ \\
& & $235 \pm 48$ & $233 \pm 77$ \\
\hline
\end{tabular}




\section{Cell experiments}

Table S3. Overview of the cell experiments. Experiments were performed with HEK-drOatp1d1 and HEK-Co cells. Two independent experiments with three replicates were conducted $(n=6)$.

\begin{tabular}{|c|c|c|c|}
\hline Substrate & Concentration substrate $(\mu \mathrm{M})$ & Inhibitor & Concentration inhibitor $(\mu \mathrm{M})$ \\
\hline \multicolumn{4}{|c|}{ Experiment: Oatp1d1-mediated transport } \\
\hline labeled BSP & 1 & / & \\
\hline Bromoxynil & 10,100 & / & \\
\hline Diclofenac & 10,100 & / & \\
\hline Carbamazepine & 10,100 & l & \\
\hline \multicolumn{4}{|c|}{ Experiment: Addition of BSP } \\
\hline labeled BSP & 1 & BSP & $0,10,100$ \\
\hline Bromoxynil & 10,100 & BSP & $0,10,100$ \\
\hline Diclofenac & 10,100 & BSP & $0,10,100$ \\
\hline Carbamazepine & 10,100 & BSP & $0,10,100$ \\
\hline \multicolumn{4}{|c|}{ Experiment: Addition of CsA } \\
\hline labeled BSP & 1 & CsA & 0,5 \\
\hline Bromoxynil & 10,100 & CsA & 0,5 \\
\hline Diclofenac & 10,100 & CsA & 0,5 \\
\hline Carbamazepine & 10,100 & CsA & 0,5 \\
\hline \multicolumn{4}{|c|}{ Experiment: Mixed exposure to bromoxynil and diclofenac } \\
\hline Bromoxynil $^{\mathrm{a}}$ & 10,100 & Diclofenac & 10,100 \\
\hline Diclofenac $^{\mathrm{a}}$ & 10,100 & Bromoxynil & 10,100 \\
\hline
\end{tabular}

${ }^{\mathrm{a} O n l y}$ performed in one independent experiment. 


\section{Section IV: UV/vis absorbance of bromosulfophthalein}

a)

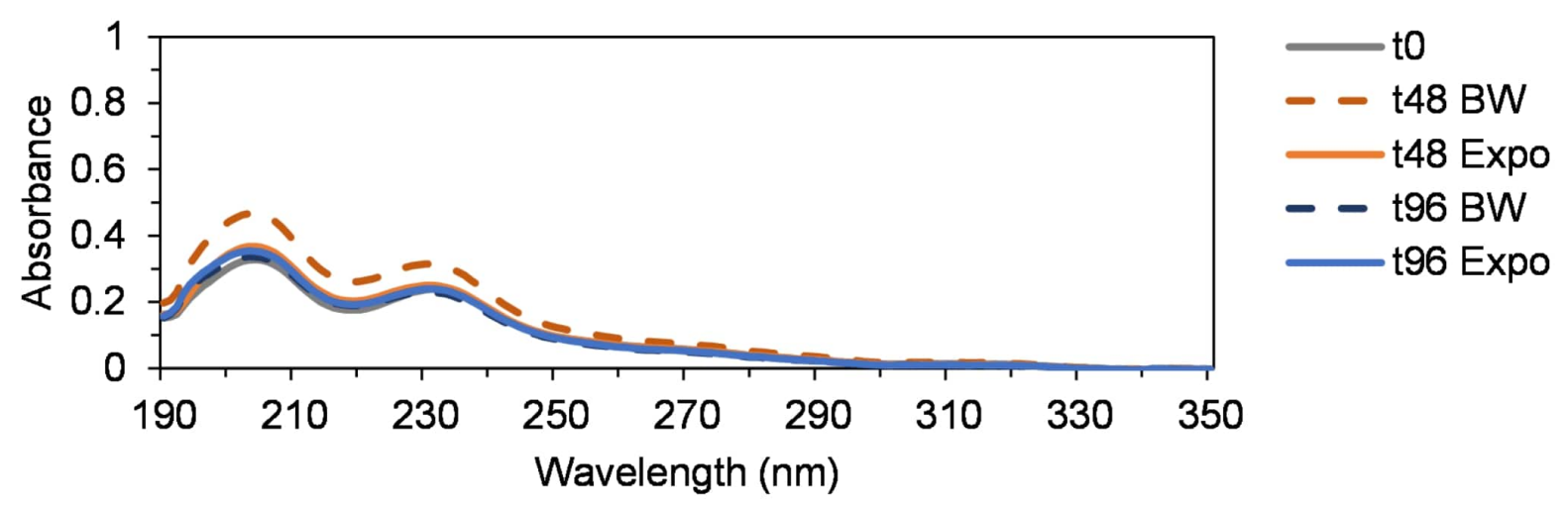

b)

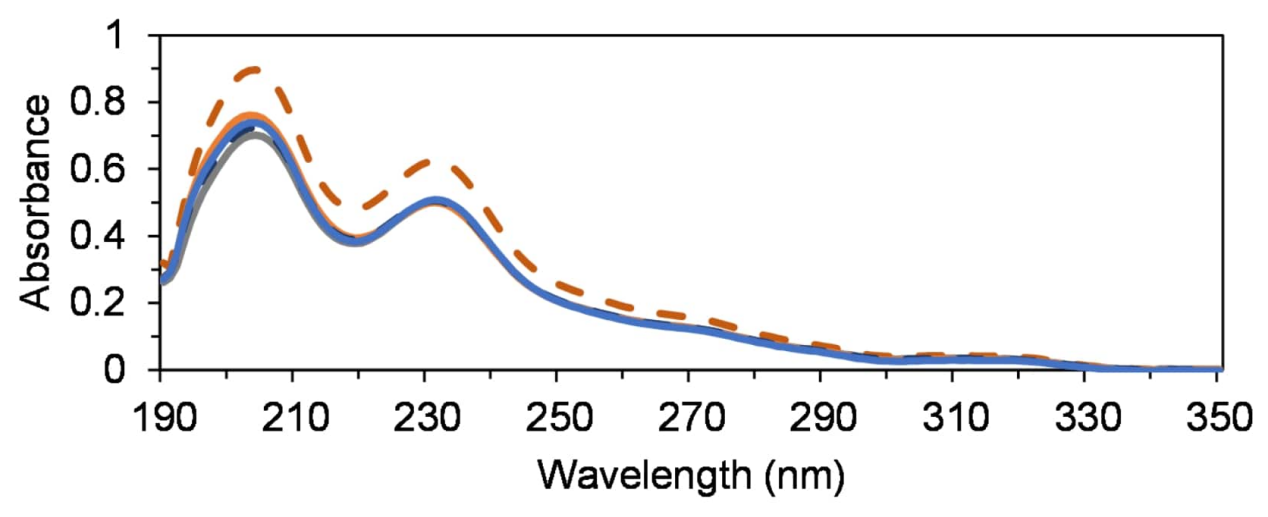

Figure S2. Absorbance measured for the bromosulfophthalein solution at a concentration of a) $50 \mu \mathrm{M}$ and b) $100 \mu \mathrm{M}$. It was measured at the beginning of exposure (grey) and after $48 \mathrm{~h}$ and $96 \mathrm{~h}$ in the blind control without embryos (BW) and in the exposure solution (Expo). 


\section{Section V: Results of cell experiments}

\section{BSP uptake}

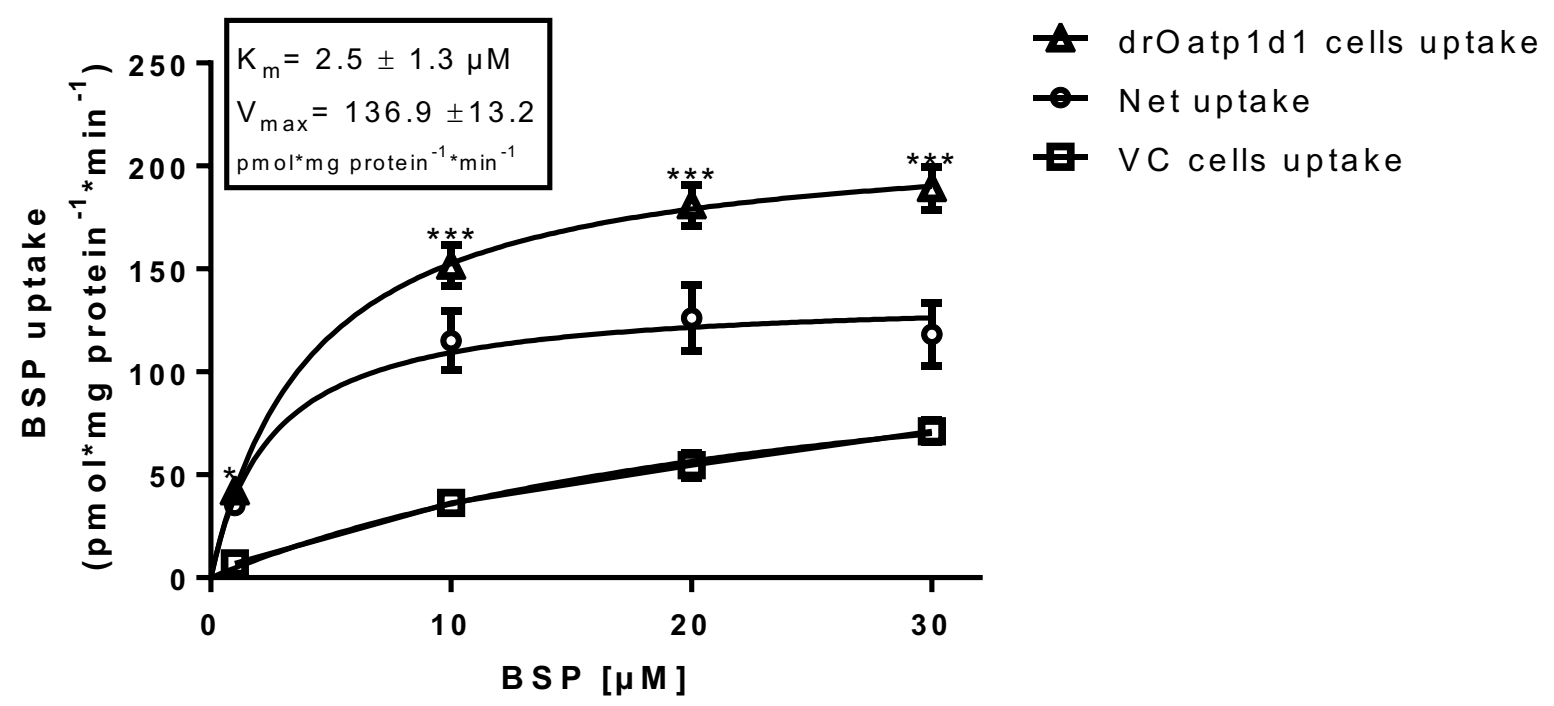

Figure S3. Uptake of labeled BSP in HEK-drOatp1d1 cells and HEK-co (VC (vector control) cells uptake), and calculated net uptake. Km-values were calculated for the net uptake with GraphPad Prism Version 5.01 with a nonlinear regression (Michaelis Menten Fit). BSP uptake was statistically compared between drOatp1d1 cells and HEK-co cells with an unpaired Student's t-test $\left(* \mathrm{p}<0.05,{ }^{* * *} \mathrm{p}<0.001\right)$. 


\section{Comparisons of HEK-Co and HEK-Oatp1d1 cells upon $100 \mu \mathrm{M}$}

incubations
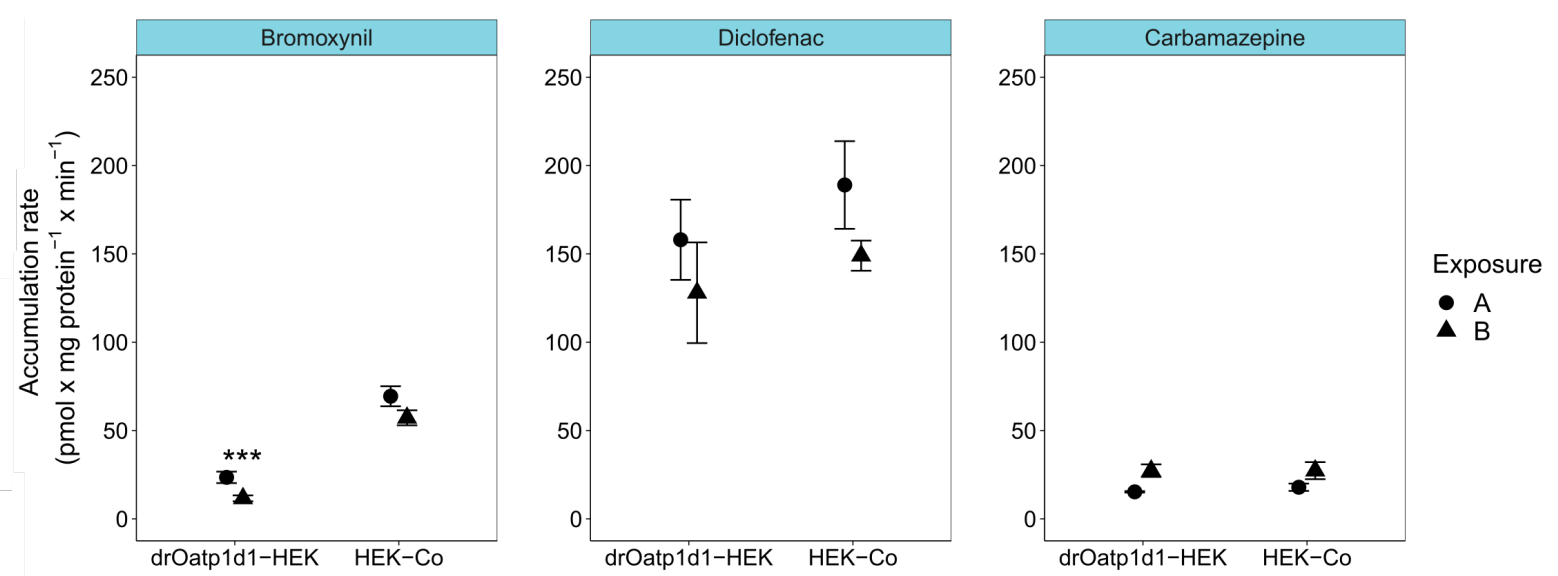

Figure S4. Accumulation rates for bromoxynil, diclofenac, and carbamazepine (100 $\mu \mathrm{M}$ incubations) in HEK-drOatp1d1 and HEK-Co cells. The incubation period was 10 minutes. The data of two independent experiments (exposures $\mathrm{A}$ and $\mathrm{B}$ ) are separately depicted; means $\pm \mathrm{SD}$ of three replicates per concentration are shown. Net transport values: -45.9 and $-45.6 \mathrm{pmol} / \mathrm{mg}$ protein $/ \mathrm{min}$ (bromoxynil), -30.6 and -21.1 (diclofenac), -2.6 and 0.1 (carbamazepine). Significant differences between accumulation rates in HEK-drOatp1d1 and HEK-co cells are indicated by asterisks (Manly's permutation test, $* * * \mathrm{p}<0.001)$. Please refer to Figure 3 for cellular accumulation data upon incubation to test compounds at $10 \mu \mathrm{M}$. 
BSP effects on uptake of bromoxynil, diclofenac and carbamazepine (100 $\mu \mathrm{M}$ incubations)
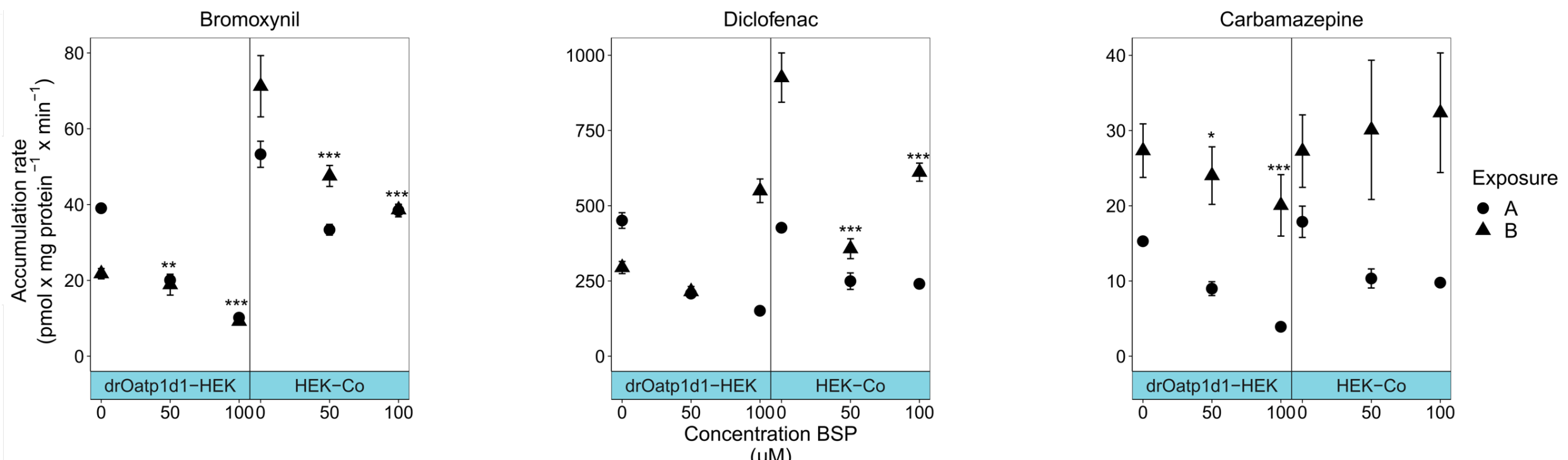

Figure S5. Accumulation of bromoxynil, diclofenac, and carbamazepine (100 $\mu \mathrm{M}$ incubations) in HEK-drOatp1d1 and in HEK-Co cells. The incubation time was $10 \mathrm{~min}$. The data of two independent experiments (exposures A and B) are separately depicted; means \pm SD of three replicates per concentration are shown. Significant differences between respective treatments with and without BSP are indicated by asterisks (Manly's permutation test, ${ }^{*} \mathrm{p}<0.05,{ }^{* *} \mathrm{p}<0.01,{ }^{* * *} \mathrm{p}<$ 0.001). Please note different scales of the y-axes. The respective net transport values are reported in Table S4. Please refer to Figure 4 for accumulation rate data upon incubation to test compounds at $10 \mu \mathrm{M}$. 
Table S4. Oatp1d1-mediated net transport (difference of the accumulation in the drOatp1d1-expressing cells and the vector control cells) of bromoxynil, diclofenac, and carbamazepine (100 $\mu \mathrm{M}$ incubation). The incubation time was $10 \mathrm{~min}$. The data of two independent experiments (exposures A and B) are separately depicted; means \pm SD of three replicates per concentration are shown. Significant differences between treatments with and without BSP are indicated by asterisks (Manly's permutation test, ** $\mathrm{p}<0.01)$. The respective accumulation rates are reported in Figure S5.

\begin{tabular}{|c|c|c|c|c|c|c|}
\hline Substance A & $\begin{array}{l}\text { Concentration } \\
\text { substance A } \\
(\mu \mathrm{M})\end{array}$ & Substance B & $\begin{array}{l}\text { Concentration } \\
\text { substance B } \\
(\mu \mathrm{M})\end{array}$ & Exposure & $\begin{array}{l}\text { Net transport } \\
\text { (pmol x mg pro }\end{array}$ & $\begin{array}{l}\text { SD } \\
\left.\operatorname{ein}^{-1} x \min ^{-1}\right)\end{array}$ \\
\hline \multirow[b]{2}{*}{ Bromoxynil } & \multirow{2}{*}{100} & \multirow{2}{*}{ BSP } & \multirow{2}{*}{0} & A & -14.2 & 3.5 \\
\hline & & & & B & -49.5 & 8.2 \\
\hline \multirow{2}{*}{ Bromoxynil } & \multirow{2}{*}{100} & \multirow{2}{*}{ BSP } & \multirow{2}{*}{50} & A & -13.3 & 2.1 \\
\hline & & & & B & -28.7 & 3.9 \\
\hline \multirow{2}{*}{ Bromoxynil } & \multirow{2}{*}{100} & \multirow{2}{*}{ BSP } & \multirow{2}{*}{100} & A & -28.3 & 1.7 \\
\hline & & & & B & -29.4 & 1.6 \\
\hline \multirow{2}{*}{ Diclofenac } & \multirow{2}{*}{100} & \multirow{2}{*}{ BSP } & \multirow{2}{*}{0} & A & 23.9 & 27.6 \\
\hline & & & & B & -631 & 84 \\
\hline \multirow{2}{*}{ Diclofenac } & \multirow{2}{*}{100} & \multirow{2}{*}{ BSP } & \multirow{2}{*}{50} & A & -41.2 & 28.6 \\
\hline & & & & B & -143 & 37 \\
\hline \multirow{2}{*}{ Diclofenac } & \multirow{2}{*}{100} & \multirow{2}{*}{ BSP } & \multirow{2}{*}{100} & A & -89.5 & 15.3 \\
\hline & & & & B & -61.7 & 49.5 \\
\hline \multirow{2}{*}{ Carbamazepine } & \multirow{2}{*}{100} & \multirow{2}{*}{ BSP } & \multirow{2}{*}{0} & A & -2.6 & 2.1 \\
\hline & & & & B & 0.062 & 6.0 \\
\hline \multirow{2}{*}{ Carbamazepine } & \multirow{2}{*}{100} & \multirow{2}{*}{ BSP } & \multirow{2}{*}{50} & A & -1.4 & 1.6 \\
\hline & & & & B & -6.1 & 10.0 \\
\hline \multirow{2}{*}{ Carbamazepine** } & \multirow{2}{*}{100} & \multirow{2}{*}{ BSP } & \multirow{2}{*}{100} & A & -5.9 & 0.5 \\
\hline & & & & B & -12.3 & 8.9 \\
\hline
\end{tabular}


CsA effects on uptake of BSP, bromoxynil, diclofenac, and carbamazepine
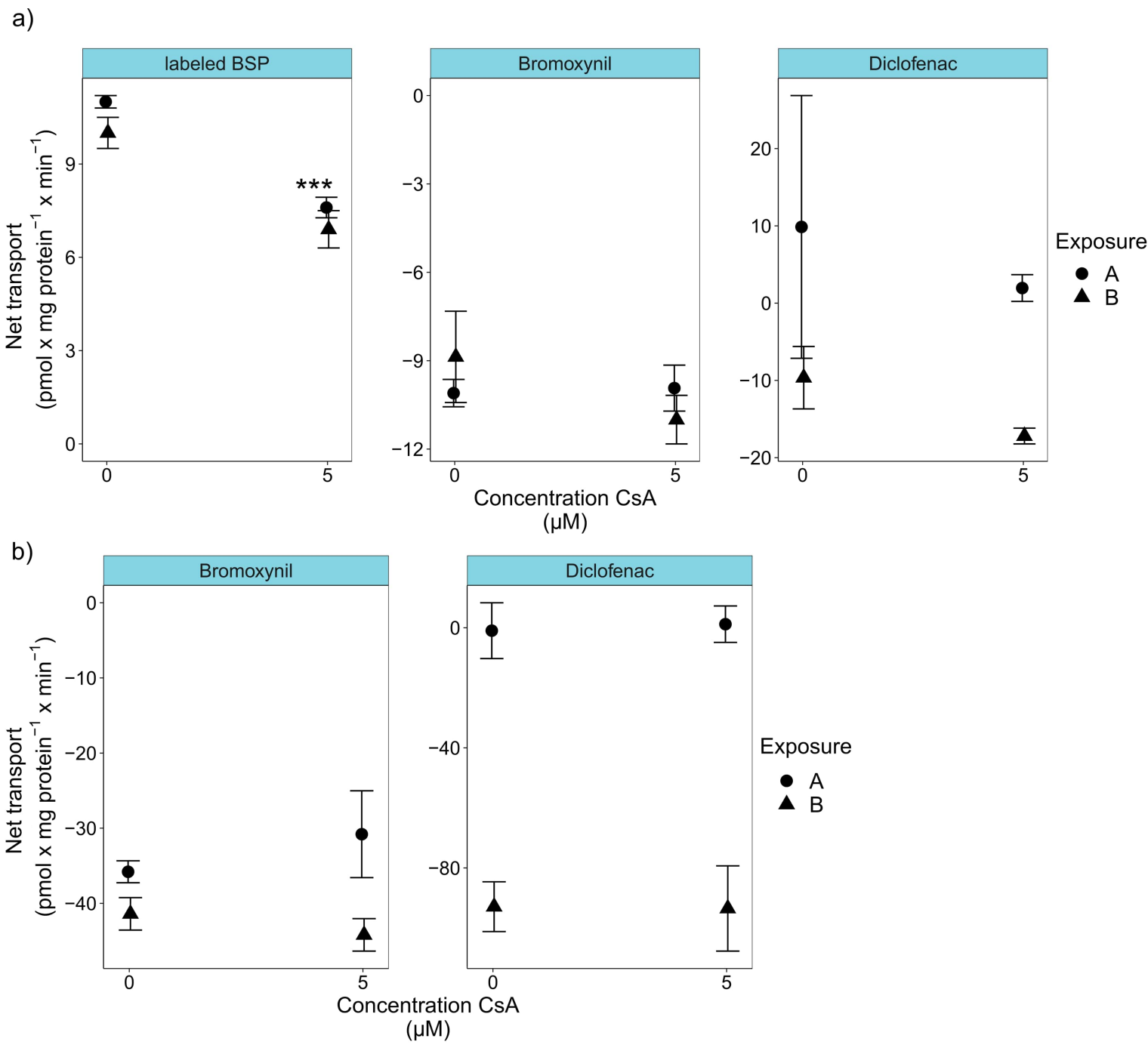

Figure S6. Effects of $5 \mu \mathrm{M}$ CsA on the uptake of (a) labeled BSP at $1 \mu \mathrm{M}$ and of bromoxynil and diclofenac, each at $10 \mu \mathrm{M}$, and of (b) bromoxynil and diclofenac, each at $100 \mu \mathrm{M}$, in drOatp1d1transfected cells. Depicted are the net transport of labeled BSP, bromoxynil, diclofenac, and carbamazepine when applied singly or in combination with CsA in a 10 min incubation. Net transport was calculated by subtracting the transport into HEK-drOatp1d1 cells from that into HEK-Co cells. Two independent experiments (exposures A and B) with 3 wells per concentration are presented as means \pm $\mathrm{SD}$, respectively. Significant differences between treatments with and without CsA are indicated by asterisks (Manly's permutation test, $* * * \mathrm{p}<0.001$ ). 
a)
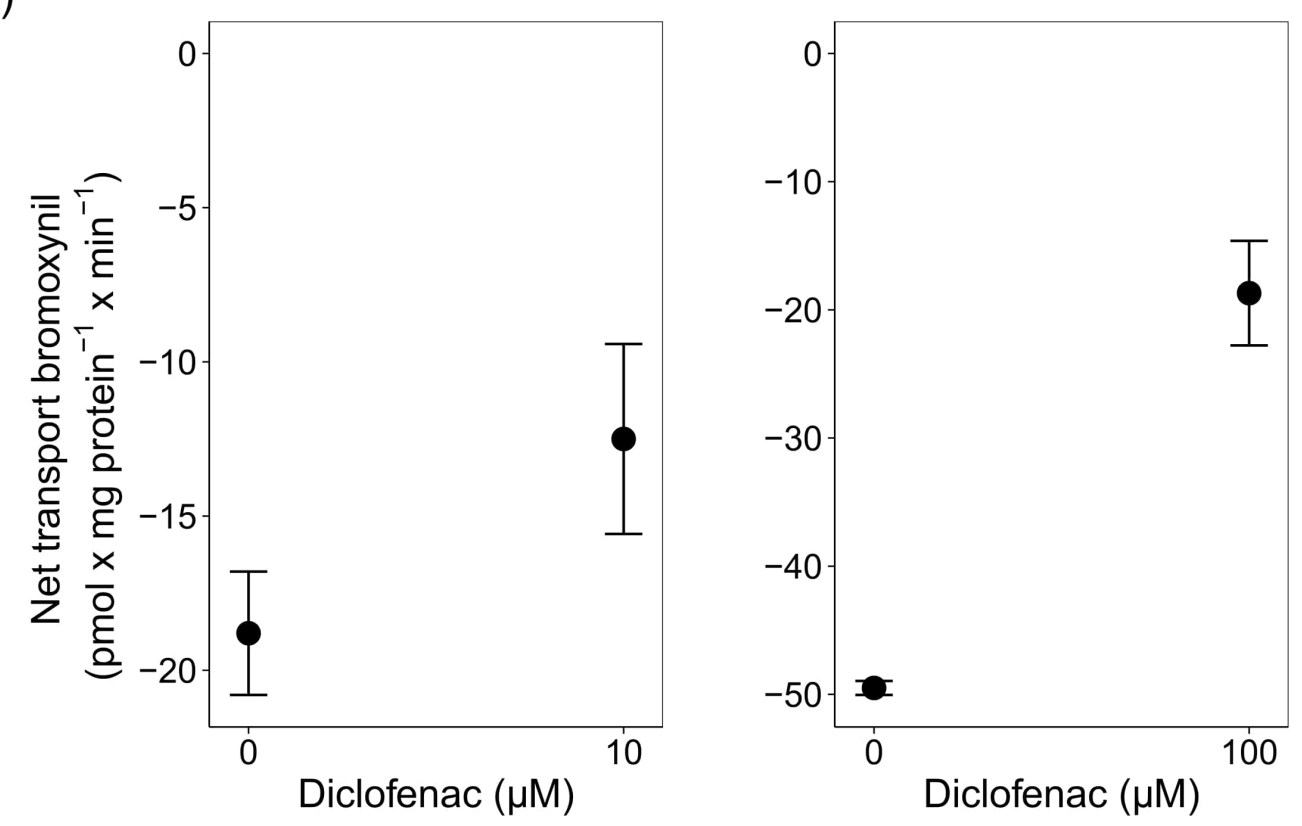

b)
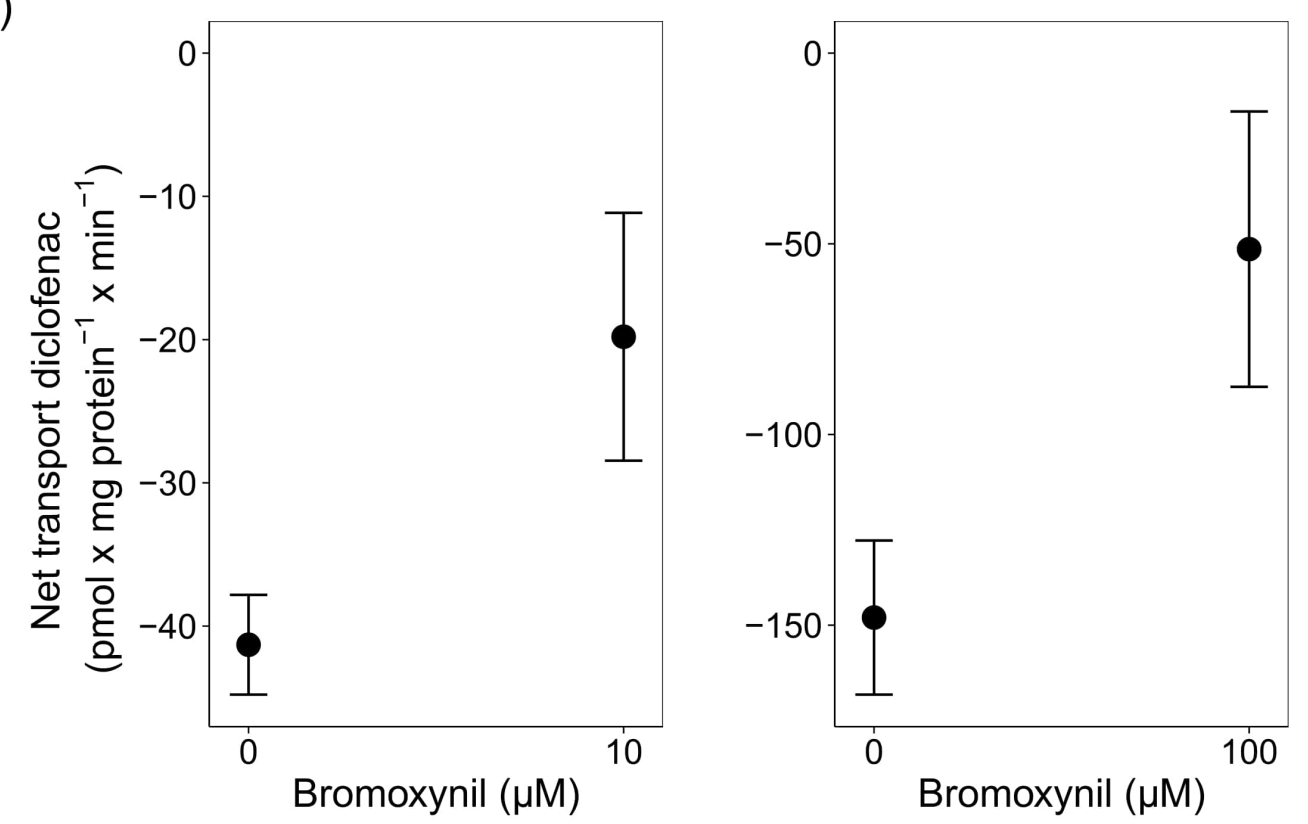

Figure S7. Effects of diclofenac and bromoxynil on the uptake of the respective other compound (expressed as net transport) in drOatp1d1-transfected cells. Depicted is the net transport of bromoxynil (a) and diclofenac (b) when applied singly or in combination with 10 (left) or $100 \mu \mathrm{M}$ (right) of the respective other compound in a $10 \mathrm{~min}$ incubation. Net transport was calculated by subtracting the transport into HEK-drOatp1d1 cells from that into HEK-Co cells. Shown are means from 3 wells per concentration (circles) $\pm \mathrm{SD}$. 


\section{Section VI: Results of zebrafish embryo exposure experiments}

Phenotype effects of the test compounds in zebrafish embryos
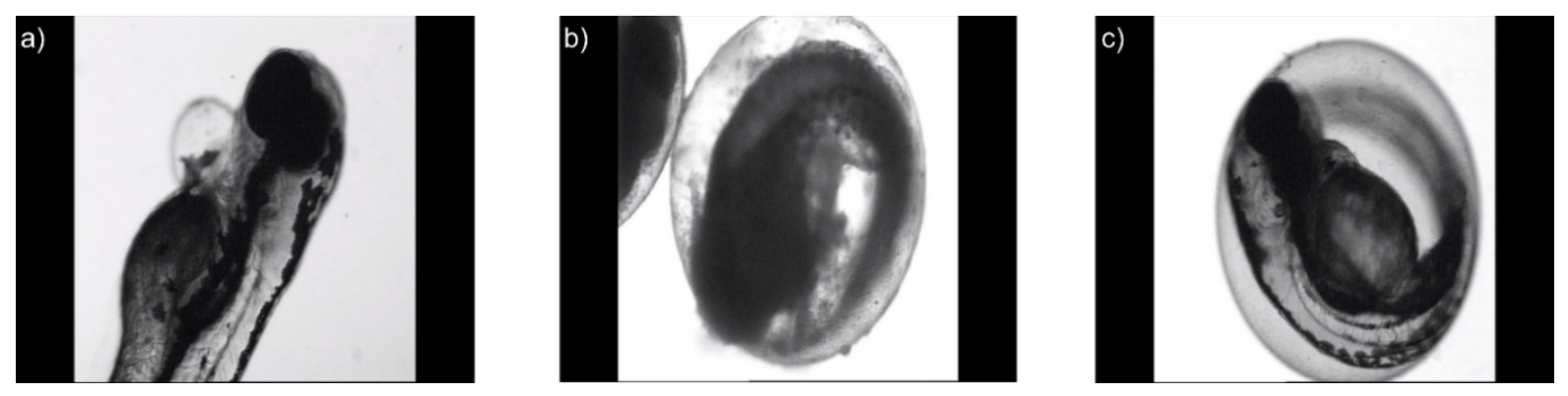

Figure S8. Microscopic photographs of zebrafish embryos with macroscopic effects exposed for $96 \mathrm{~h}$ to a) diclofenac (at EC25) with $50 \mu \mathrm{M}$ BSP (edema pericard), b) bromoxynil (at EC25) with $100 \mu \mathrm{M}$ BSP (coagulation), c) carbamazepine (EC25) with $100 \mu \mathrm{M}$ BSP (no hatching). 
Table S5. Toxicities of the test compounds for zebrafish embryos in $24 \mathrm{~h}$ exposures starting at $1 \mathrm{hpf}$ (Experiment 2). The term "total effects" comprises lethal and sublethal (phenotypic) effects. For measured concentrations of EC5 and EC25 values refer to Table S2. k: coagulation; mtail: tail deformation; nodt: no detachment of tail; nosf: no formations of somites; ret: retardation

\begin{tabular}{|c|c|c|c|c|}
\hline \multirow{2}{*}{$\begin{array}{l}\text { Substance A (exposure } \\
\text { concentration) }\end{array}$} & \multirow{2}{*}{$\begin{array}{l}\text { Substance B } \\
\text { (exposure } \\
\text { concentration) }\end{array}$} & \multirow{2}{*}{$\begin{array}{l}\text { Total effects [\%] } \\
\text { Experiment } 2 \mathrm{~A}\end{array}$} & \multirow{2}{*}{$\begin{array}{l}\text { Total effects [\%] } \\
\text { Experiment 2B }\end{array}$} & \multirow[t]{2}{*}{ Effects } \\
\hline & & & & \\
\hline Control & & 0 & 0 & \\
\hline $\operatorname{BSP}(50 \mu \mathrm{M})$ & & 0 & 0 & \\
\hline $\mathrm{BSP}(100 \mu \mathrm{M})$ & & 0 & 0 & \\
\hline Bromoxynil (EC5) & & 0 & 0 & \\
\hline Bromoxynil (EC5) & $\mathrm{BSP}(50 \mu \mathrm{M})$ & 0 & 0 & \\
\hline Bromoxynil (EC5) & $\operatorname{BSP}(100 \mu \mathrm{M})$ & 8 & 0 & $\mathrm{k}$ \\
\hline Bromoxynil (EC25) & & 8 & 0 & $\mathrm{k}$ \\
\hline Bromoxynil (EC25) & $\mathrm{BSP}(50 \mu \mathrm{M})$ & 0 & 8 & ret, nodt, nosf \\
\hline Bromoxynil (EC25) & $\mathrm{BSP}(100 \mu \mathrm{M})$ & 0 & 0 & \\
\hline Diclofenac (EC5) & & 0 & 0 & \\
\hline Diclofenac (EC5) & $\mathrm{BSP}(50 \mu \mathrm{M})$ & 0 & 17 & $\mathrm{k}$ \\
\hline Diclofenac (EC5) & $\operatorname{BSP}(100 \mu \mathrm{M})$ & 8 & 0 & $\mathrm{k}$ \\
\hline Diclofenac (EC25) & & 0 & 17 & $\begin{array}{l}\mathrm{k} \text {, ret, nodt, } \\
\text { nosf }\end{array}$ \\
\hline Diclofenac (EC25) & $\mathrm{BSP}(50 \mu \mathrm{M})$ & 0 & 0 & \\
\hline Diclofenac (EC25) & $\operatorname{BSP}(100 \mu \mathrm{M})$ & 0 & 0 & \\
\hline Carbamazepine (EC5) & & 0 & 0 & \\
\hline Carbamazepine (EC5) & $\mathrm{BSP}(50 \mu \mathrm{M})$ & 17 & 0 & $\mathrm{k}$ \\
\hline Carbamazepine (EC5) & $\operatorname{BSP}(100 \mu \mathrm{M})$ & 0 & 0 & \\
\hline Carbamazepine (EC25) & & 17 & 8 & $\mathrm{k}$, mtail \\
\hline Carbamazepine (EC25) & $\mathrm{BSP}(50 \mu \mathrm{M})$ & 0 & 0 & \\
\hline Carbamazepine (EC25) & $\operatorname{BSP}(100 \mu \mathrm{M})$ & 0 & 0 & \\
\hline
\end{tabular}


Table S6. Toxicities of the test compounds for zebrafish embryos in $24 \mathrm{~h}$ exposures starting at $72 \mathrm{hpf}$ (Experiment 3). The term "total effects" comprises lethal and sublethal (phenotypic) effects. For measured concentrations of EC5 and EC25 values refer to Table S2. mtail: tail deformation; sco: scoliosis; (beh: observation of less movement)

\begin{tabular}{|c|c|c|c|c|}
\hline $\begin{array}{l}\text { Substance A (exposure } \\
\text { concentration) }\end{array}$ & $\begin{array}{l}\text { Substance B } \\
\text { (exposure } \\
\text { concentration) }\end{array}$ & $\begin{array}{l}\text { Total effects [\%] } \\
\text { Experiment 3A }\end{array}$ & $\begin{array}{l}\text { Total effects [\%] } \\
\text { Experiment 3B }\end{array}$ & Effects \\
\hline Controls & & 0 & 0 & \\
\hline $\mathrm{BSP}(50 \mu \mathrm{M})$ & & 0 & 0 & \\
\hline $\mathrm{BSP}(100 \mu \mathrm{M})$ & & 0 & 0 & \\
\hline Bromoxynil (EC5) & & 0 & 0 & \\
\hline Bromoxynil (EC5) & $\mathrm{BSP}(50 \mu \mathrm{M})$ & 17 & 0 & sco \\
\hline Bromoxynil (EC5) & $\mathrm{BSP}(100 \mu \mathrm{M})$ & 0 & 0 & \\
\hline Bromoxynil (EC25) & & 0 & 0 & \\
\hline Bromoxynil (EC25) & $\mathrm{BSP}(50 \mu \mathrm{M})$ & 0 & 0 & \\
\hline Bromoxynil (EC25) & $\mathrm{BSP}(100 \mu \mathrm{M})$ & 0 & 0 & \\
\hline Diclofenac (EC5) & & 0 & 0 & \\
\hline Diclofenac (EC5) & $\mathrm{BSP}(50 \mu \mathrm{M})$ & 0 & 0 & \\
\hline Diclofenac (EC5) & $\mathrm{BSP}(100 \mu \mathrm{M})$ & 8 & 0 & mtail \\
\hline Diclofenac (EC25) & & 0 & 0 & \\
\hline Diclofenac (EC25) & $\mathrm{BSP}(50 \mu \mathrm{M})$ & 0 & 0 & \\
\hline Diclofenac (EC25) & $\mathrm{BSP}(100 \mu \mathrm{M})$ & 0 & 0 & \\
\hline Carbamazepine (EC5) & & 0 & 0 & (beh) \\
\hline Carbamazepine (EC5) & $\mathrm{BSP}(50 \mu \mathrm{M})$ & 0 & 0 & (beh) \\
\hline Carbamazepine (EC5) & $\mathrm{BSP}(100 \mu \mathrm{M})$ & 0 & 0 & (beh) \\
\hline Carbamazepine (EC25) & & 0 & 0 & (beh) \\
\hline Carbamazepine (EC25) & $\mathrm{BSP}(50 \mu \mathrm{M})$ & 0 & 0 & (beh) \\
\hline Carbamazepine (EC25) & BSP $(100 \mu \mathrm{M})$ & 0 & 0 & (beh) \\
\hline
\end{tabular}


Table S7. Toxicities of the test compounds for zebrafish embryos in $96 \mathrm{~h}$ exposures starting at $1 \mathrm{hpf}$ (Exposure experiment 1). The term "total effects" comprises lethal and sublethal (phenotypic) effects. For measured concentrations of EC5 and EC25 values refer to Table S2. nohb: no heartbeat; nobc: no blood circulation; EdP: edema pericard; hf: heart frequency

\begin{tabular}{lllll}
\hline $\begin{array}{l}\text { Substance A } \\
\text { (exposure } \\
\text { concentration) }\end{array}$ & $\begin{array}{l}\text { Substance B } \\
\text { (exposure } \\
\text { concentration) }\end{array}$ & $\begin{array}{l}\text { Mortality [\%] } \\
\text { Experiment 1A }\end{array}$ & $\begin{array}{l}\text { Total effects [\%] } \\
\text { Experiment 1A }\end{array}$ & Effects \\
\hline $\begin{array}{llll}\text { Bromoxynil (EC5) } \\
\text { Diclofenac (EC5) }\end{array}$ & 0 & 0 & EdP, no hatching \\
Bromoxynil (EC5) & Diclofenac (EC5) & 10 & 27 & hf, no hatching \\
Bromoxynil (EC25) & 5 & 71 & nohb, nobc \\
Diclofenac (EC25) & 0 & 10 & EdP \\
Bromoxynil (EC25) & Diclofenac (EC25) & 40 & 43 & $\begin{array}{l}\text { EdP, nohb, no } \\
\text { hatching }\end{array}$ \\
\hline
\end{tabular}


Internal concentrations upon mixed exposure to bromoxynil and diclofenac

a)
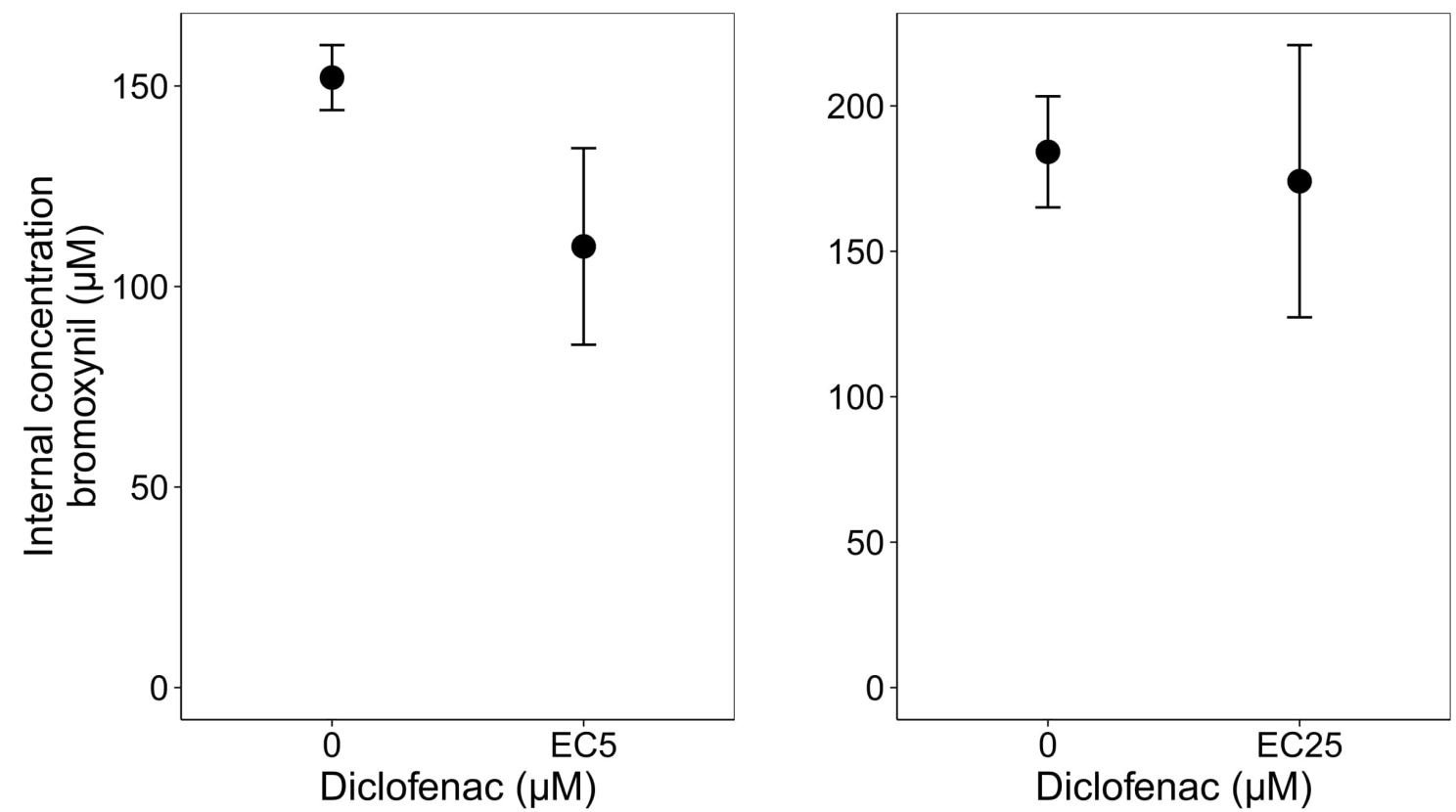

b)
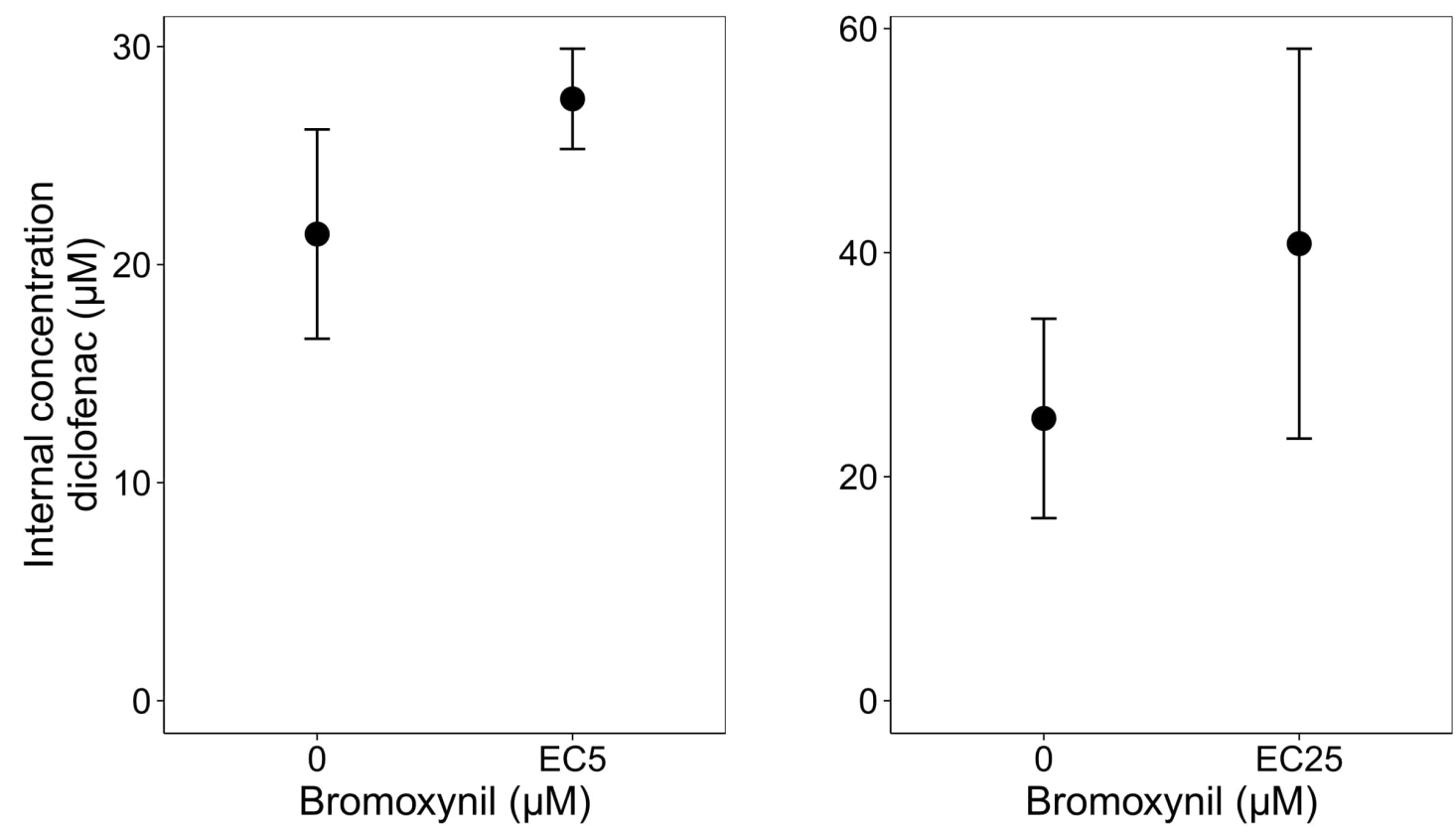

Figure S9. Effects of diclofenac and bromoxynil on the uptake of the respective other compound (expressed as internal concentration) in zebrafish embryos. Depicted is the internal concentration of bromoxynil (a) and diclofenac (b) when applied singly or in combination with EC5 (left) or EC25 (right) of the respective other compound. Shown are means from three replicates from one egg batch consisting of three pooled embryos (circles) \pm SD. 


\section{Section VII: MS imaging}

\section{MALDI-MS imaging: Peaks of three bromoxynil isotopes}

a)
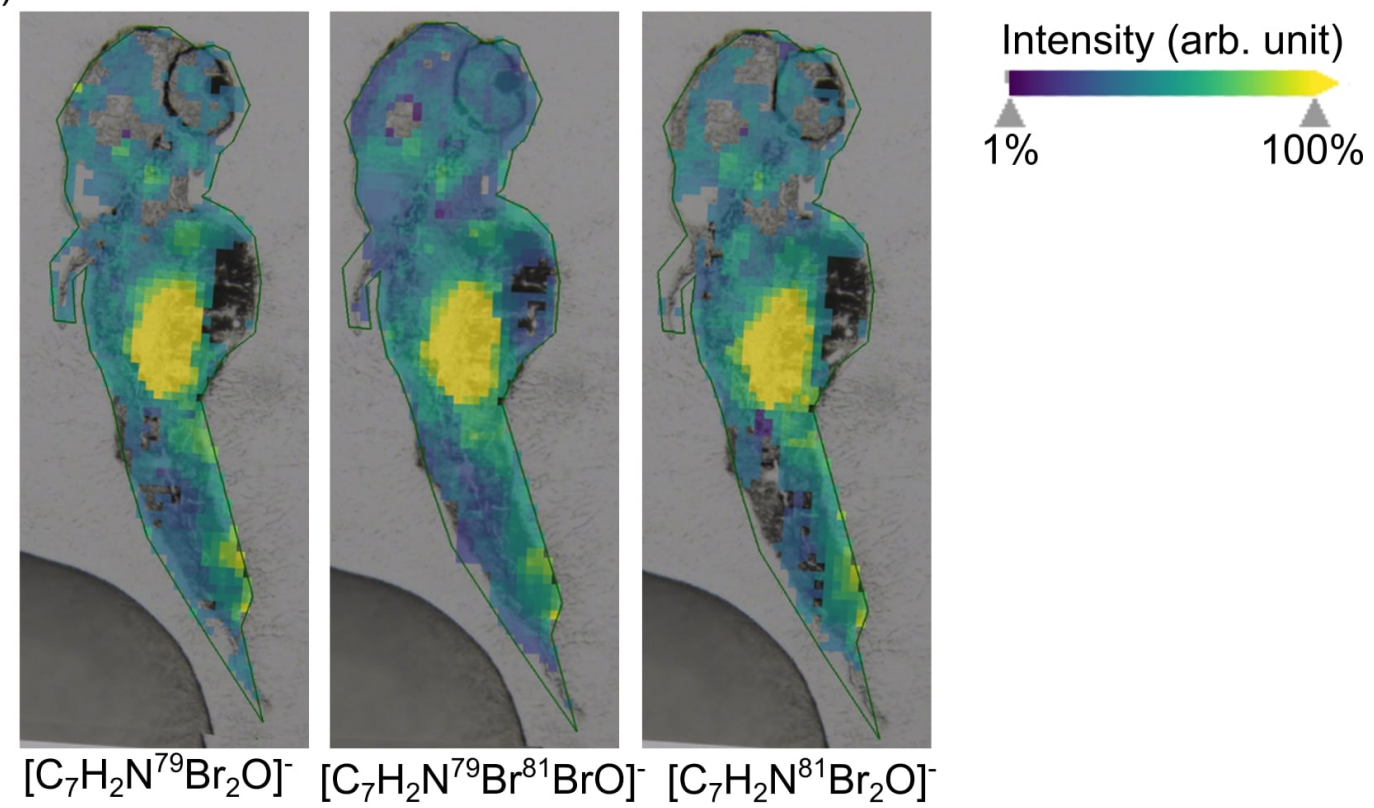

b)

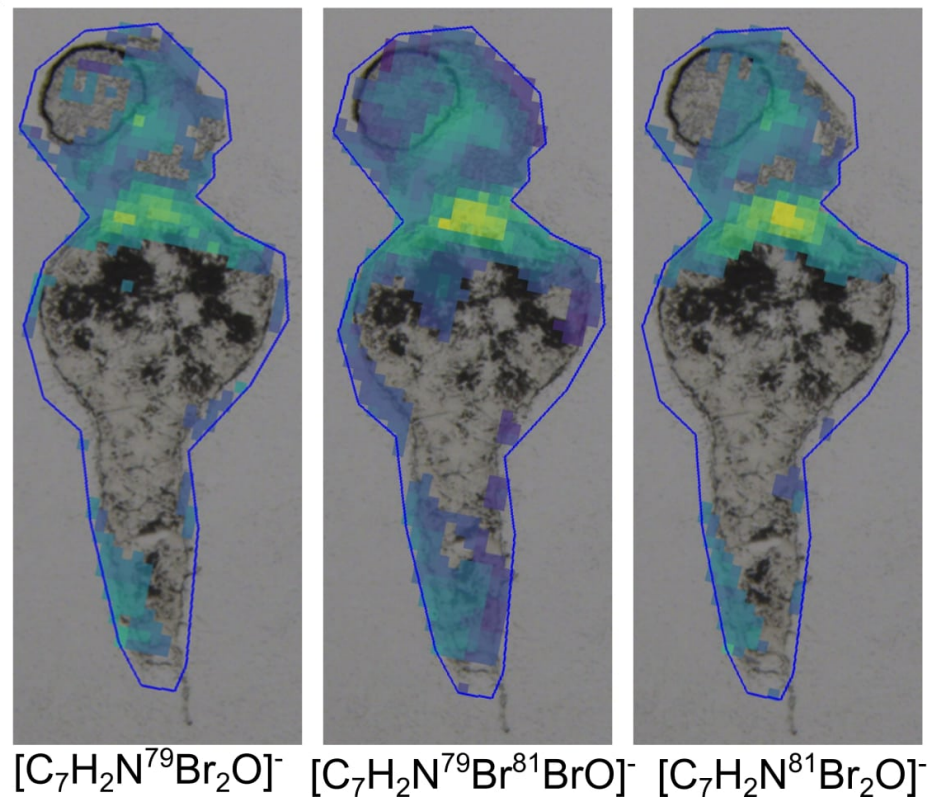

Figure S10. Distribution of bromoxynil isotopes: $\left[\mathrm{C}_{7} \mathrm{H}_{2} \mathrm{~N}^{79} \mathrm{Br}_{2} \mathrm{O}\right]^{-}(273.84877 \mathrm{~m} / \mathrm{z} \pm 0.30818 \mathrm{mDa})$, $\left[\mathrm{C}_{7} \mathrm{H}_{2} \mathrm{~N}^{79} \mathrm{Br}^{81} \mathrm{BrO}\right]^{-}(275.84671 \mathrm{~m} / \mathrm{z} \pm 0.19313 \mathrm{mDa})$, and $\left[\mathrm{C}_{7} \mathrm{H}_{2} \mathrm{~N}^{81} \mathrm{Br}_{2} \mathrm{O}\right]^{-}(277.8447 \mathrm{~m} / \mathrm{z} \pm 0.27828$ $\mathrm{mDa}$ ) in two exposed zebrafish embryos ( $\mathrm{a}$ and $\mathrm{b}$ ). The colored line shows the measured area. The exposure duration was $72 \mathrm{~h}$. The color bar shows the range from low (purple) to high bromoxynil intensity (yellow). 


\section{LA-ICP-MS negative control}

a)

b)
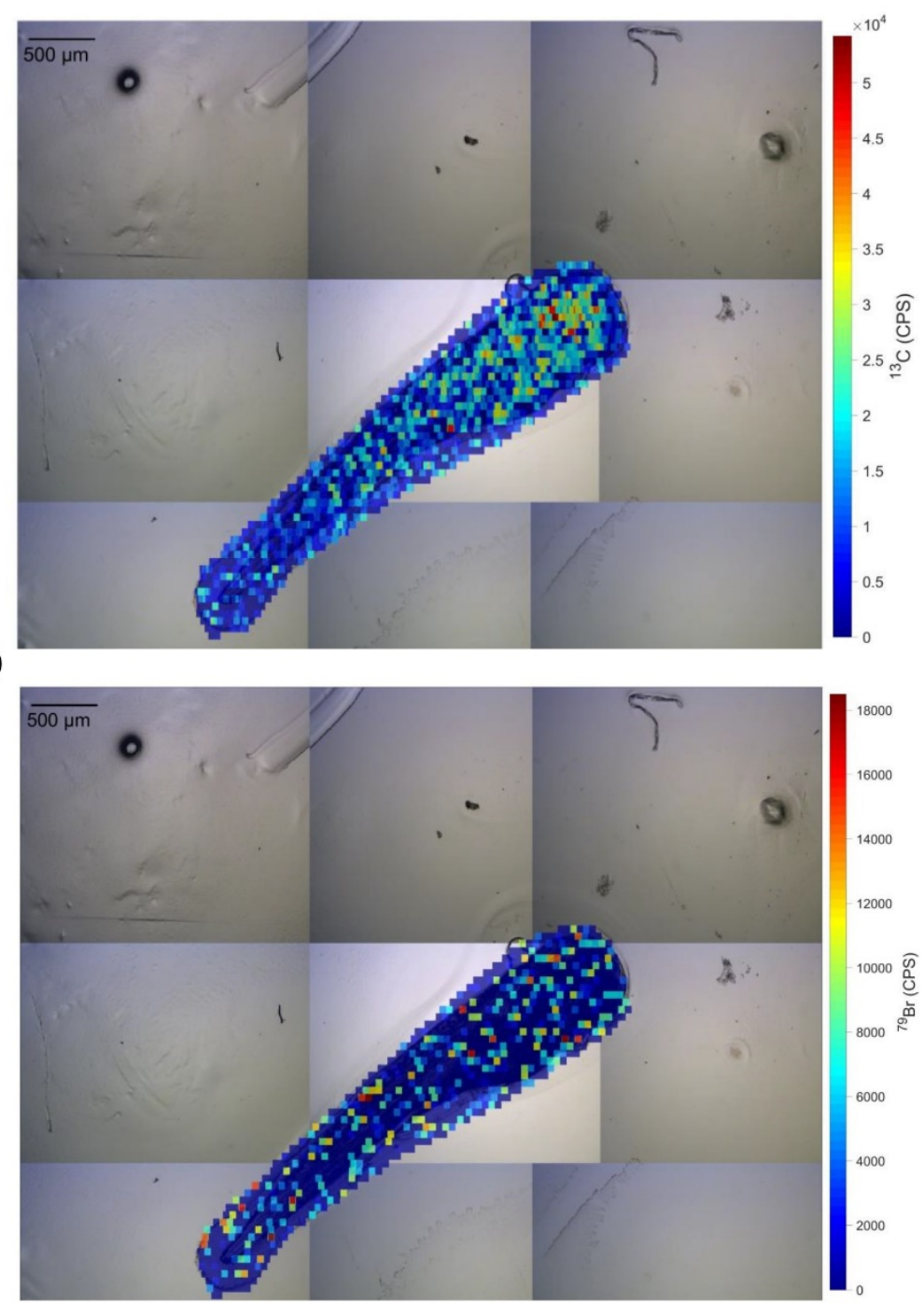

c)

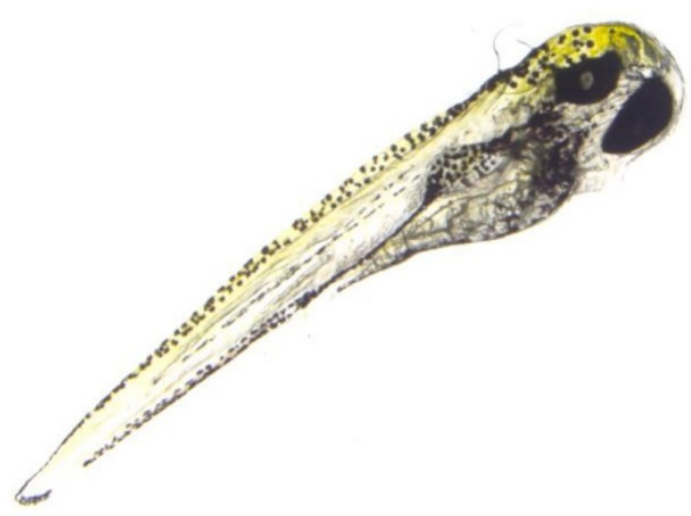

Figure S11. LA-ICP-MS results of zebrafish embryo exposed for $96 \mathrm{~h}$ to ISO-water (negative control). The intensity of the $13 \mathrm{C}$ distribution (a), 79Br intensity (b), and microscopic picture before the ablation (c) are shown. 


\section{References}

(1) ISO. Water quality - Determination of the acute toxicity of waste water to zebrafish eggs (Danio rerio). ISO 15088:2007(E). International Organisation for Standardization: 2007.

(2) Hankin, J. A.; Barkley, R. M.; Murphy, R. C. Sublimation as a method of matrix application for mass spectrometric imaging. $J$ Am Soc Mass Spectr 2007, 18 (9), 1646-1652. DOI: 10.1016/j.jasms.2007.06.010.

(3) Halbach, K.; Ulrich, N.; Goss, K. U.; Seiwert, B.; Wagner, S.; Scholz, S.; Luckenbach, T.; Bauer, C.; Schweiger, N.; Reemtsma, T. Yolk sac of zebrafish embryos as backpack for chemicals? Environ Sci Technol 2020, 54 (16), 10159-10169. DOI: 10.1021/acs.est.0c02068.

(4) Danio rerio solute carrier organic anion transporter family, member 1D - Nucleotide - NCBI. https://www.ncbi.nlm.nih.gov/nuccore/NM_001348086.1 (accessed 2021 Feb. 3). 